\title{
Effect of Loading on the Adhesion and Frictional Characteristics of Top Layer Articular Cartilage Nanoscale Contact: A Molecular Dynamics Study- supporting information
}

Abhinava Chatterjee, Devendra K. Dubey* and Sujeet K. Sinha

Mechanical Engineering Department, Indian Institute of Technology Delhi, Hauz Khas, New Delhi 110016, India

*Corresponding author

Corresponding author email: $\underline{\text { dkdubey@mech.iitd.ac.in }}$

Number of pages: - 4

Number of Figures: - 1

Number of Tables: - 2 


\section{Calculation of Interfacial force in all three directions}

Force is applied on the topmost black layer and the interfacial forces in $\mathrm{x}-, \mathrm{y}-, \mathrm{z}$ - directions are calculated on the green layer of the bottommost part of the slider due to the pink layer of the substrate as shown in Figure 13. The entire simulation consists of initial equilibration for 100ps, then 10ps of loading and followed by final equilibration and then pull-off or sliding test.

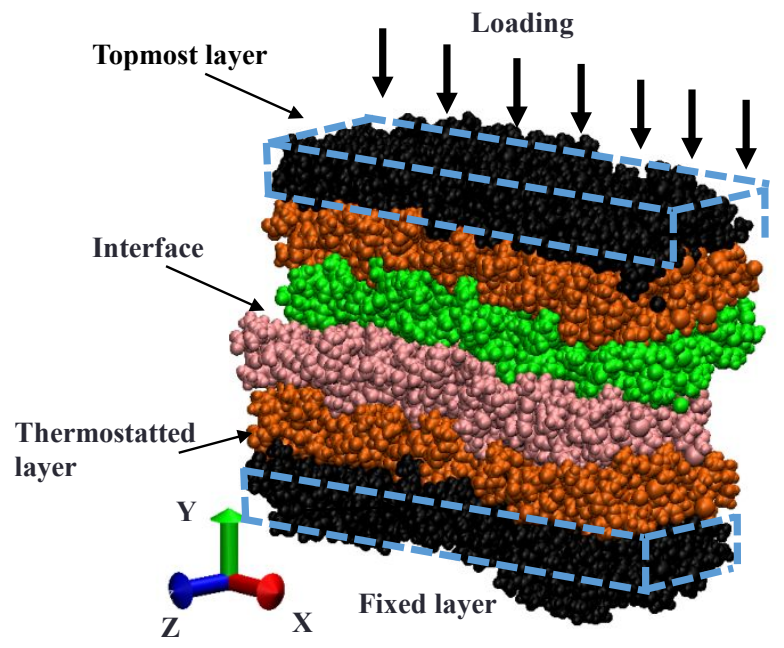

(a)

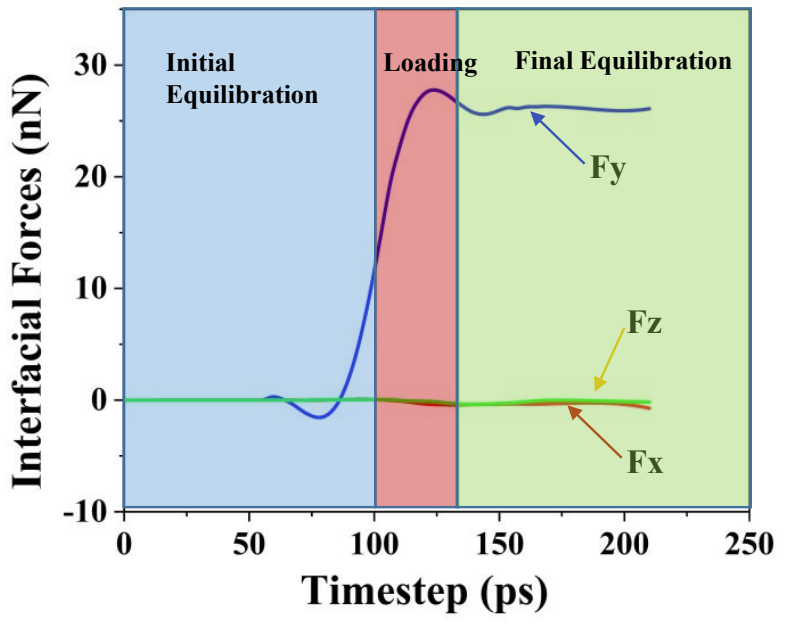

(b)

Figure S1. Measurement of Interfacial forces of the interface atomistic model before onset of sliding. (a) Atomistic model after final equilibration (b) Interfacial forces vs Timestep in x-,y-,zdirection. Loading is performed in y-direction.

\section{Calculation of Equivalent contact stress}

Total no of atoms in the atomistic model $=17172$

No of atoms in the topmost layer $=2850$

Added force $=$ Number of atoms $*$ Loading rate in $(\mathrm{Kcal} / \mathrm{mole}-\mathrm{A})=2850 * .07194=205.029$

$\mathrm{Kcal} / \mathrm{mole}-\mathrm{A}=14.25 \mathrm{nN}$

$=$ Force $*$ Conversion factor $(\mathrm{Kcal} / \mathrm{mole}-\mathrm{A}$ to $\mathrm{pN})=205.029 * 69.5=14249.5 \mathrm{pN}$

Model dimension of the atomistic model $\left(\mathrm{X}^{*} \mathrm{Y} * \mathrm{Z}\right)=87.759 \AA * 120 \AA * 42.286 \AA$

Contact Stress at the interface $=0.385 \mathrm{GPa}=385 \mathrm{MPa}$

\section{Simulation Methodology and Parameters}


The systematic methodology of conducting Non equilibration molecular dynamics (NEMD) for the top layer unhydrated cartilage-cartilage contact at bodily conditions are as follows.

Table S1 shows the parameters and values considered for conducting the pull-off tests for a range of loads.

\section{Table S1. Parameters for conducting Pull-off tests}

\begin{tabular}{|c|c|}
\hline Parameters & Values \\
\hline Configuration & Three dimensional \\
\hline Material & $\begin{array}{l}\text { Collagen fragments in form of slider and } \\
\text { substrate }\end{array}$ \\
\hline Contact geometry & Flat on Flat \\
\hline Dimensions of the atomistic model & $86 \AA$ x $98 \AA \AA$ x $42 \AA$ \\
\hline Total Number of atoms & 17172 \\
\hline Force field & CHARMM27 \\
\hline Periodic boundary conditions & $\begin{array}{l}\text { Periodic in } \mathrm{x} \text { and } \mathrm{z} \text {; Non periodic in } \mathrm{y}- \\
\text { direction }\end{array}$ \\
\hline Non bonded cutoff distance & $13 \AA$ \\
\hline Timestep & $0.5 \mathrm{fs}$ \\
\hline \multirow[t]{5}{*}{ Load } & Case1:3.5 nN (Contact \\
\hline & Pressure $(p)=96.25 \mathrm{MPa}) \mathbf{L 3 . 5}$ \\
\hline & Case 2: $7 \mathrm{nN}(\mathrm{p}=192.5 \mathrm{MPa}) \mathbf{L} 7$ \\
\hline & Case $3: 14 \mathrm{nN}(\mathrm{p}=385 \mathrm{MPa}) \mathbf{L 1 4}$ \\
\hline & Case 4: $28 \mathrm{nN}(\mathrm{p}=770 \mathrm{MPa}) \mathbf{L 2 8}$ \\
\hline Velocity & $1 \mathrm{~m} / \mathrm{sec}=0.0001 \AA / \mathrm{fs}$ in \\
\hline Direction of pulling & In y-direction \\
\hline Sliding Distance & $15 \AA$ \\
\hline Ensemble used & Canonical ensemble \\
\hline Total duration of simulation & 1500 picoseconds (ps) \\
\hline Temperature & $310 \mathrm{~K}$ (Human body temp $=37^{\circ} \mathrm{C}$ ) \\
\hline
\end{tabular}

Table S2 shows the simulation methodology and parameters and their values considered for conducting the sliding tests for a range of loads.

Table S2. Sliding Simulation Methodology and parameters

\begin{tabular}{lc}
\hline \multicolumn{1}{c}{ Parameters } & Values \\
\hline Configuration & Three dimensional \\
Material & Collagen fragments in form of slider and \\
& substrate \\
Contact geometry & Flat on Flat \\
Dimensions of the atomistic model & $86 \AA \times 98 \AA \mathrm{x} 42 \AA$ \\
Total Number of atoms & 17172 \\
Force field & CHARMM27 \\
Periodic boundary conditions & Periodic in x and z; Non periodic in y-direction \\
Non bonded cutoff distance & $13 \AA$ \\
Ensemble & NVE (Adiabatic)
\end{tabular}


Timestep

Load

Velocity

Direction of sliding

Sliding Distance

Thermostatting

Total duration of simulation

Temperature
$0.5 \mathrm{fs}$

Case 1:3.5 nN (p=96.25MPa) $\quad$ L3.5 X/Z

Case 2: $7 \mathrm{nN}(\mathrm{p}=192.5 \mathrm{MPa}) \quad \mathbf{L 7} \mathbf{X} / \mathbf{Z}$

Case $3: 14 \mathrm{nN}(\mathrm{p}=385 \mathrm{MPa}) \quad \mathbf{L 1 4} \mathbf{X} / \mathbf{Z}$

Case 4: $28 \mathrm{nN}(\mathrm{p}=770 \mathrm{MPa}) \quad \mathbf{L 2 8} \mathbf{X} / \mathbf{Z}$ $1 \mathrm{~m} / \mathrm{sec}=0.0001 \AA / \mathrm{fs}$

In $\mathrm{X}$ - and z- direction; Denoted in LLoadX/Z $15 \AA$

Langevin dynamics

1.5 nanoseconds (ns)

$310 \mathrm{~K}$ (Human body temp $=37^{\circ} \mathrm{C}$ ) 